\title{
Erratum to: Long-term in situ monitoring at Dashgil mud volcano, Azerbaijan: a link between seismicity, pore-pressure transients and methane emission
}

\author{
Achim Kopf • Georg Delisle • Eckhard Faber • \\ Behrouz Panahi $\cdot$ Chingiz S. Aliyev • \\ Ibrahim Guliyev
}

Published online: 4 February 2010

(C) Springer-Verlag 2010

\section{Erratum to: Int J Earth Sci (Geol Rundsch) DOI 10.1007/s00531-009-0487-4}

Owing to an error in the spreadsheet containing our global data base on methane flux, we have confused data published by Etiope et al. (2007). Their flux estimate for seepage and mud volcanoes is $3,000 \mathrm{t} / \mathrm{y}$, or $0.003 \mathrm{Tg} / \mathrm{a}$. For individual domes, the flux hence amounts to $0.0024 \mathrm{Tg} / \mathrm{a}$ (their Table 2), a very realistic value. We apologise to our colleagues for the mistakes in the original manuscript, which clearly led us to the wrong conclusions and very unfortunately misrepresents their research.

In fact, in a different paper Etiope et al. (2004) estimate the methane flux from the bubbling "large salse" of Dashgil MV to be $\sim 500 \mathrm{t} / \mathrm{y}$ ( or $\sim 0.0005 \mathrm{Tg} / \mathrm{a}$ ), a value which shows an astonishing agreement with our long-term data set (this study) given that the authors based their numbers only on a short period of investigation.

The online version of the original article can be found under doi:10.1007/s00531-009-0487-4.

\footnotetext{
A. $\operatorname{Kopf}(\bowtie)$

MARUM Research Centre, University Bremen,

P.O. Box 330440, 28334 Bremen, Germany

e-mail: akopf@uni-bremen.de

G. Delisle · E. Faber

Bundesanstalt für Geowissenschaften und Rohstoffe,

Stilleweg 2, 30561 Hannover, Germany

e-mail: Georg.Delisle@bgr.de

B. Panahi · C. S. Aliyev · I. Guliyev

Geological Institute, Azerbaijan National Academy of Sciences,

H. David Ave. 29A, 370143 Baku, Azerbaijan

e-mail: bpanahi@gia.ab.az
}

With respect to Lusi mud volcano, we want to specify a statement in our manuscript regarding the link between earthquakes and mud volcanic activity after a personal communication with A. Mazzini (2010). We noted that such a correlation does not exist, however, at least postseismically an increase in flow rate may be inferred at May 29, June 1, and September 10 as well as 24, 2006 (hard to see in Mazzini et al. 2007, their Fig. 5 owing to the size and resolution of the illustration). For additional data, the reader may refer to Mazzini et al. (2009).

We thank our colleagues Giuseppe Etiope and Adriano Mazzini for kindly having pointed out these errors, and acknowledge their significant contributions to mud volcano research.

Finally, we want to draw the reader's attention to the fact that during typesetting and editorial layout, the captions of Figs. 7 and 8 got swapped although they were in the correct positions in the manuscript proofs.

Etiope et al. (2007) and Mazzini et al. (2007) are already cited in the original manuscript.

\section{References}

Etiope G, Feyzullayev A, Baciu CL, Milkov AV (2004) Methane emission from mud volcanoes in eastern Azerbaijan. Geology 32(6):465-468

Mazzini A, Nermoen A, Krotkiewski M, Podladchikov Y, Planke S, Svensen H (2009) Strike-slip faulting as a trigger mechanism for overpressure release through piercement structures. Implications for the Lusi mud volcano, Indonesia. Mar Petrol Geol 26:17511765 